\title{
Analysis on Current Situation of English Broadcast of Passenger Cabin and Its Countermeasures
}

\author{
Jie $\mathrm{Hu}$ \\ Civil Aviation Flight University of China, Guanghan 618307, China
}

Keywords: Passenger cabin; English broadcast; current situation; countermeasures

\begin{abstract}
International Civil Aviation Organization has clearly specified that English is its special language. The correctness of broadcast and the quickness of information transfer are important standards for the English broadcast quality. At present, English broadcast of passenger cabin of China's civil aviation is dissatisfactory and has not reached its desired effects. In view of this, English broadcast of passenger cabin is summarized, the current situation of English broadcast of passenger cabin in China is analyzed and countermeasures of improving English broadcast of passenger cabin are put forward in this paper.
\end{abstract}

\section{Introduction}

Considering the current continuous development of China's economy, increasingly rise of people's living standard, continuous increase of international communication and more and more foreigners coming to China for sightseeing, business and settling, the high-quality English broadcast for foreigners on a plane will directly affect the reputation of aviation enterprise. The analysis of the current situation of English broadcast of passenger cabin in China can better give play to the propaganda function of English broadcast of passenger cabin and is conducive to the better exchange and communication between China and other countries.

\section{Overview of English broadcast of passenger cabin}

English broadcast of passenger cabin mainly means that the flight attendants express their thoughts and feelings and communicate with passengers in English by virtue of some specific vocabularies, tone and intonation as well as body language during passenger cabin service. It is a standard and flexible communication mode and manifests the level of civilization. The main contents of English broadcast of passenger cabin include aircraft structure, flight situation, aerogeography knowledge, introduction of relevant scenic spots, air service etc., characterized by soft, clear, pure, simple and others. The reasonable application of English in the air can convey rich information to every passenger, which can not only convey ideas and feelings, but also can clear the air, make people close and enhance the mutual understanding. English broadcast quality of passenger cabin is a highlight that embodies the air service level of Chinese aviation enterprises and will directly affect the feelings of passengers on the plane and the grand image of passenger cabin service. English broadcast may fail due to any frivolous misconduct, so the broadcaster should improve their quality at all aspects because passengers will lose confidence in the aviation enterprise due to the bad broadcast quality, thus inevitably causing irretrievable great losses. English broadcast of passenger cabin is arranged according to time, service sequence and security management procedure. The broadcast must be layered and clear and conduct in-depth analysis from specific service and security management.

\section{Analysis of current situation of English broadcast of passenger cabin in China}

\section{(I) Not solid basic skills of English language}

Basic skills of English language are one of the basic carriers of realizing passenger cabin communication and also key factors that affect and restrain the improvement of English broadcast level of passenger cabin in the actual English broadcast of passenger cabin. According to the 
investigation, the basic skills of English language of passenger cabin in China mainly have the following four problems:

First, the pronunciation is not standard. This is one of the important problems concerning poor English broadcast quality of passenger cabin and exists in most of the non-standard broadcasts of passenger cabin. This problem is closely related to the broadcaster's English foundation, regional characteristics of dialect, pronunciation habits and other factors, with complex and diversified forms. The author focuses on discussing several common phenomena in the non-standard English broadcast of passenger cabin. For example, as there are no such phonetics as $[\theta]$ and [ð] in Chinese, the broadcaster often replaces them with other phonetics, such as [f], $[\mathrm{s}]$ and [z], due to the interference of mother language. According to the author's investigation, most of the broadcasters of passenger cabin cannot distinguish the difference of "southern" and "thousand". Although there are also vowel problems, but the non-standard pronunciation of $[\theta]$ and [ð] is still the main factor. At the same time, the non-standard pronunciation of final consonants is also a prominent problem in English broadcast of passenger cabin. For example, glass ([gla:s]) is often read [gla:si] and sleep ([sli: p]) is read as [sili: pu] and room ([ru:m]) is read as [rumu].

Second, the light tone and stress of a word are not distinguished. This is also one of the important factors that the broadcast quality of passenger cabin cannot achieve the expected effects. According to the investigation, the author knows that among the general service words of passenger cabin broadcast, the stress error of "refreshment", "beverage", "entertainment" and other words is common mainly because the above words have too many syllable and the stress is not on the first or multiple syllable, so the light tone and stress are not distinguished, thus seriously affecting the broadcast quality and directly causing communication failure.

Third, there is serious sound swallowing phenomenon due to improper read-through caused by speed pursuit. The reason for this problem is that the broadcaster may swallow the inflexion, if any. For example, Your life vest is locat (ed) under your seat. It may only be us (ed) in case of a water landing. Please do not remove it unless instruct (ed) by one of your flight attendants. Some broadcasters may swallow the inflexion in the bracket. At the same time, other broadcasters swallow the sound consciously as they lack of confidence in read-through, for example, "invite you" - "invi you". In case of continuous sound swallowing phenomena, it is hard to achieve the expected aim.

Fourth, the stress and the weak form in English sentences are not distinguished and there is no change of intonation and tone. The psychological change of broadcaster may also cause language problem. In case of a sentence with numbers, the broadcaster often pays great attention to the numbers, thus leading to improper stress. For example, The distance between Beijing and Guangzhou is 3000 kilometers. Our flight will take ' 3 hours and ' 45 minutes. We expect to arrive at Baiyun airport at ' $4 \mathrm{pm}$. At the same time, when listing something, the original intonation change will be neglected, thus leading to poor English broadcast quality.

\section{(II) Lacking of English broadcast skills}

First, awkward broadcast tone and lacking of cordiality. If passenger cabin broadcasters are full of warmth and cordiality in their heart, their broadcast must be warm and cordial. On the contrary, if the broadcasters fail to do this during broadcasting, the broadcast must be plain and dead, lacking of ups and downs and changes.

Second, lacking purpose and object. The object means that the broadcaster should have someone in her heart in the unpeopled working environment. If the broadcaster fails to do this, the broadcast must be simple and dead, lacking of ups and downs, or like soliloquy or repeat, which cannot arouse passengers' interest and make them sleepy.

\section{Countermeasures of improving English broadcast of passenger cabin}

\section{(I) Enhance the training of English ability of flight attendants}

As the passenger cabin broadcast belongs to unidirectional communication, the language problem of flight attendants cannot be corrected timely and effectively under this circumstance, thus leading to fossilization, that is, the English defects of flight attendants cannot be feed back and 
corrected timely, thus leading to long-term existence of such defects. Therefore, it is necessary to conduct on-the-job training of English language, which can be off-the-job or not off-the-job, but it must be conducted under a circumstance of error correction. The author thinks the use of video equipment for Micro-teaching is a good on-the-job training form. The Micro-teaching, also called video feedback teaching, is devoted to overcome the one-dimensional property of time and present the teaching process to learners by making full use of video recording technology to make them experience such process as a student and then find their problems and make improvement under the help of tutor and other group members. The on-the-job English training of flight attendants should be conducted by employees with professional knowledge of air service and English teaching because only the professional with the above professional knowledge can effectively improve the broadcast ability of flight attendants from passenger cabin air service and English teaching; otherwise, only partial effects can be achieved.

\section{(II) Strengthen the training of broadcast skills of flight attendants}

The broadcast skills refer to the professional skills in addition to the language competence and the satisfactory effects can be achieved only after professional tutoring and training. The specific method is to firmly master the object because every broadcast has audiences. When the broadcaster completes the broadcast, the passengers should be clear about what the broadcaster has said. The broadcaster should pay attention to the feelings of audiences. The broadcaster should have someone in her heart in the unpeopled working environment. The broadcaster should master the tone. The tone is a form of sound expressed under the control of thoughts and feelings, in which the thoughts and feelings are the soul and the form of voice is the body. The thoughts and feelings are the basis for language expression. If the broadcaster is full of warmth and cordiality in their heart, their broadcast must be warm and cordial. The broadcaster should also master the rhythm. Rhythm is the reciprocation of verbal language caused by the ups and downs of certain thought and feeling during broadcasting. In the passenger cabin broadcast, passengers are willing to accept the light and leisure rhythm, which gives them cordiality and warmth as well as a sense of leisure at home.

\section{(III) Improve the proportion of English ability upon selecting new flight attendants}

The main objective of air attendants is to conduct communication, so the communication ability of candidates should be prior during selecting the new air attendants, thus, the language competence, especially the English foundation, will be highly concerned and the proportion of English ability will be improved in the selection standard, which can effectively improve the current situation of passenger cabin broadcast. For this, the oral English test of high reliability can be used, for example, there are two interviewers - communicator and evaluator - during interview, for which the former is mainly responsible for grasping the interview process and rating the English ability of candidate and the former is mainly responsible for evaluating the details of the English ability of candidate and obtaining the final scores of such candidate after weighting. Thus, the interview will better and effectively quantify the English ability of each candidate.

\section{(IV) Fully consider the balance of English ability during crew configuration}

Due to the short-term foreign language broadcast of China's aviation industry and other historical factors, the English broadcast ability of in-service flight attendants are different. Therefore, the most effective, economical and practical way to improve the English broadcast quality of passenger cabin is to conduct scientific combination of current flight attendants, specially all-process quantitative management of English broadcast ability of passenger cabin servers to make the English ability of crews balanced and complete the passenger cabin broadcast excellently.

\section{Conclusion}

In conclusion, under the current situation, English broadcast of passenger cabin can provide various required information for passengers, which is very important. The understanding of the current situation of English broadcast of passenger cabin can better give play to the propaganda role of English broadcast. English broadcast of passenger cabin has a huge development potential and space, so the English broadcast level of passenger cabin can be improved from quality, features, cultivation of broadcasters and other aspects by reference to the current situation of English 
broadcast of passenger cabin of western countries.

\section{References}

[1] Liu Hui, Liang Yueqiu. Air Service Communication and Broadcasting Skills (2nd Edition)[M]. Beijing: Tourism Education Press, 2007.

[2] Zhu Yan. Let China's Voice Spread Across the World_— Thinking on English News Report[J]. Journal of Hunan Mass Media Vocational Technical College, 2008(5).

[3] Pei Yuxin, Pei Yingzheng. On Correction of English Pronunciation[J]. Journal of Shanxi Finance and Economics University, 2011(11).

[4] Xing Lina. Problems Should be Noticed in Listening to English News Broadcast[J]. China Newspaper Industry, 2011(22). 